\title{
Colorectal Emergencies: Review and Controversies in the Management of Large Bowel Obstruction
}

\author{
Heather L. Yeo • Sang W. Lee
}

Received: 30 May 2013 / Accepted: 26 August 2013 / Published online: 19 September 2013

(C) 2013 The Society for Surgery of the Alimentary Tract

\begin{abstract}
Introduction Traditionally, large bowel obstruction (LBO) has been managed as an operative emergency. Its causes and treatments are an important part of general surgical and colon and rectal surgery practices.

Discussion While management has traditionally been emergent laparotomy with resection or removal of underlying pathology, newer methodologies and treatments over the last decade have required treating physicians to consider a number of other options, including nonoperative options such as stenting, when treating these patients.

Conclusion Given these changes, treating a patient with LBO requires a thoughtful assessment and comprehensive understanding of underlying pathology, assessment of the patient's comorbidities and up-to-date knowledge of modern options for treatment.
\end{abstract}

Keywords Large bowel obstruction · Colonic obstruction · Obstructing colon cancer

\section{Introduction}

Traditionally, large bowel obstruction (LBO) has been managed as an operative emergency. ${ }^{1}$ Its causes and treatments are an important part of general surgical and colon and rectal surgical practices. While management has classically been emergent laparotomy with resection or removal of underlying pathology, newer methodologies and treatments over the last decade have required treating physicians to consider a number of other options, including nonoperative options such as stenting when treating these patients. Given these changes, treating a patient with LBO requires a thoughtful assessment and comprehensive understanding of underlying pathology, assessment of the patient's comorbidities and up-to-date knowledge of modern options for treatment.

H. L. Yeo ( $ه)$

Memorial Sloan Kettering Cancer Center, 1275 York Avenue, New

York, NY 10065, USA

e-mail: yeoh@mskcc.org

S. W. Lee

New York Presbyterian Hospital, Weill Cornell Medical College,

1315 York Avenue 2nd floor, New York, NY 10021, USA
We plan to discuss etiology, symptoms, diagnosis, and controversies in the management of LBO in the current era of endoscopy and minimally invasive surgery, with a focus on recent treatment developments, controversies, and recommendations.

\section{Etiology}

Large bowel obstruction most commonly occurs in the elderly. The majority of LBOs are due to neoplasms, most often colon cancer, which accounts for just over $50 \%$ of LBOS. ${ }^{2,3}$ In fact, around $10 \%$ of colon cancers initially present with LBO.

The most common sites of malignant obstruction are the descending colon and rectosigmoid. Volvulus accounts for another $10-17 \%$ of LBO and arises from an axial rotation around the mesentery. ${ }^{3}$ Volvulus most often occurs in the sigmoid colon or in the cecum. Diverticular strictures are the cause of around $10 \%$ of LBO. Acute diverticulitis can also cause colonic obstruction due to abscess compression, stricture, or inflammation. Cecal bascule is an uncommon cause of obstruction. Other rare causes of obstruction include intussusception, Crohn's, extrinsic tumors, fecal impaction, foreign body, or infection. Other diagnoses on the differential of colonic obstruction are functional such as acute (toxic) or chronic megacolon and "Ogilvie syndrome." Adhesion related obstruction is rare. 


\section{Symptoms}

Patients with LBO usually present with abdominal pain, distention, and obstipation. Emesis is less common a symptom and presents late in the course of obstruction. Presentation depends on underlying etiology. Obstruction may be acute as in the case of volvulus but is more chronic in the case of cancers. Pain often occurs over a distended cecum because that is the area of the large bowel that is the most susceptible to distension according to La Place's law.

Patients with untreated LBO may have signs of dehydration, sepsis, distension, a palpable mass, ascites, or peritoneal signs. Detecting when an LBO is an acute surgical emergency, i.e., perforation, is largely based on clinical signs and symptoms. High fever, tachycardia, and peritonitis suggest strangulation, perforation, or ischemia and usually require an urgent laparotomy.

\section{Diagnosis}

As with any surgical disorder, a focused history and physical are important in narrowing the differential. It is important to determine whether the course is acute, as often with volvulus, or more chronic, as with obstruction from cancer. A review of symptoms should focus on recent bowel changes, changes in weight or factors that incite pain. Medical history should include whether the patient has had chronic constipation or diarrhea, a history of narcotic use, and any surgical history.

On physical exam, important findings include distension, tympany, mass, or peritonitis. A nodal exam should be completed to evaluate for metastatic disease as obstructive tumors often present late. A digital rectal exam should be performed assessing for rectal mass or blood. And, if possible, proctoscopy should be completed to evaluate for sigmoid volvulus or sigmoid mass.

Initial blood work should include a $\mathrm{CBC}$ to evaluate for anemia or an elevated WBC, a basic metabolic panel to figure out electrolyte or acid-base abnormalities and is necessary before a contrast CT scan would be ordered. A lactic acid may help to determine the degree of ischemia, if any is suggested. If a cancer is diagnosed, a complete staging workup should be done including CEA and a CT of the chest, abdomen, and pelvis, in addition to a completion once the obstruction has been dealt with.

\section{Imaging}

Plain abdominal films are usually the first diagnostic imaging performed because they are quick, inexpensive, and can help give a sense of the underlying pathology and rule out free intraperitoneal air. In some cases of volvulus or megacolon, plain will be the only necessary diagnostic test. ${ }^{4}$ The risk of perforation increases when the diameter of the cecum exceeds $10 \mathrm{~cm}$. Chapman et al. report that an abdominal three-way has $84 \%$ sensitivity and $72 \%$ specificity in identifying LBO. ${ }^{5}$ While reasonable at identifying an LBO, plain film does not provide any information on the underlying cause.

Contrast enema has traditionally been the gold standard for diagnosis of LBO and remains an important clinical tool. Water-soluble contrast is given as an enema and then a plain film is obtained. This can help to delineate the level of obstruction with $96 \%$ sensitivity and $98 \%$ specificity, and in some cases may be therapeutic. ${ }^{5}$ The drawbacks of contrast enema are patient discomfort and availability of the study.

In order to identify the location of occlusion, underlying etiology such as mass or any other signs of inflammation or perforation, a CT scan is indicated so long as the patient is hemodynamically stable and does not have signs of acute peritonitis that would indicate a need to go directly to the operating room. CT when associated with multiplanar reconstruction has a sensitivity of $83 \%$, specificity of $93 \%$, and an accuracy of $91 \%$ in determining the presence of ischemic complications. $^{6-9}$ In addition, it helps to provide detailed information about the severity of obstruction from sources such as diverticular disease, obstructive masses, or internal hernias. CT is much more readily available and easier to order in most practices. ${ }^{10}$

Radiologic findings associated with LBO include air/fluid levels within dilated loops of colon and failure of contrast to pass distally. In addition, if there is a point of obstruction, a luminal caliber change is usually noted.

\section{Differential}

Differentiation between total mechanical obstruction versus partial obstruction or pseudo-obstruction is critical because the first is typically treated surgically, whereas the others may be treated with medication or simple bowel rest. Imaging will play a key role in this distinction. Even with imaging, it often can be difficult to distinguish large bowel obstruction from colonic pseudo-obstruction. In fact, one third of patients diagnosed with LBO on clinical exam and abdominal $\mathrm{x}$-rays have colonic pseudo-obstruction, and one fifth of those initially diagnosed with colonic pseudo-obstruction actually have an underlying $\mathrm{LBO}^{2}$

CT scan can be helpful to distinguish this as patients with pseudo-obstruction or megacolon will not have a transition point or definitive area of caliber change.

Under any modality, cecal dilation can be a sign of impending perforation and should be taken seriously. Typically the upper limit of a point that leads to ischemia and perforation is about $12 \mathrm{~cm}$. There have been some reports of cecal perforation at smaller diameters, and the risk does 
depend on acuity — as slower processes may be able to tolerate a more dilated cecum. ${ }^{11}$

\section{Management}

\section{Initial Resuscitation}

Patients with LBO are usually intravascularly depleted and sequester fluids. As a result of this third spacing, they often need volume resuscitation in conjunction with other measures. In addition, if patients have vomiting, they may have further electrolyte and fluid losses, and nasal-gastric tube placement should be considered. Supportive care and resuscitation should be undertaken immediately after assessment, even before a definitive diagnosis has been made.

Both as part of the diagnosis of LBO and its management, flexible sigmoidoscopy should be considered early in the management so long as a patient is stable. In patients with a rectal mass, sigmoidoscopy may be used for initial diagnosis. Perforations are rare, and the flexible sigmoidoscopy can be done without any sedation or anesthetic. For patients with volvulus, a "swirl sign" is often seen. Especially important for patients with obstruction is that $\mathrm{CO}_{2}$ insufflation is used. Regular air insufflation may be associated with higher rates of perforation and may make an obstruction worse. The $\mathrm{CO}_{2}$ insufflation is absorbed 250 times faster than air and less likely to cause inadvertent proximal colonic distension. $^{12}$

\section{Surgical}

Even today patients with perforation, closed loop obstruction with ischemia, or peritonitis still require emergent laparotomy. A few preoperative considerations should be considered. As mentioned above, appropriate fluid and electrolyte repletion is important prior to surgery. Appropriate preoperative antibiotics should be given with both good aerobic and gramnegative coverage. Patients should have preoperative stomal marking while awake and sitting upright if possible. In addition, the risks of surgery should be discussed with the patient's family and the patient. If the patient is sick, the family should be made aware that the hospital course could be long and may include prolonged intubation or the possibility of an open abdomen. For the procedure, appropriate perioperative anticoagulation should be given so long as the patient is not septic. Patients should generally be placed in a modified lithotomy position so that if needed access to the rectum is possible. Anesthesia should be made aware of the surgeon's concerns prior to incision and be prepared for additional fluid resuscitation as needed. Traditional management of LBO has been an emergent exploratory laparotomy. If obstruction is a tumor in the right or transverse colon, primary resection and anastomosis should be considered as long as bowel looks viable and patient is hemodynamically stable and fit for resection. ${ }^{13}$ If resection is more distal, treatment is more controversial, and proximal diversion is often the procedure of choice. Obviously, surgery depends on the site of obstruction, the viability of the obstructed bowel, and the overall patient condition. Traditional three-stage surgery is rarely performed. More often, a two-stage procedure is performedwith either resection of the obstructed segment or cancer and primary anastomosis with or without diversion or with resection and a Hartmann's procedure.

Hartmann's operation was initially introduced in 1923 by Henri Hartmann as a procedure for resection of lower sigmoid and upper rectal cancers. The majority are performed during emergency situations. ${ }^{14,15}$ Morbidity is often high (up to $35 \%$ ), and they are often not reversed, with up to $45 \%$ of patients remaining with a permanent colostomy. ${ }^{16,17}$ If feasible to perform a primary anastomosis with a proximal diversion in lower rectal cancers, this is preferable but can often not be done in an emergency situation. If a patient is unstable, creation of an anastomosis is not advisable. However, in carefully selected patients with obstructing colon cancer who are hemodynamically stable, primary resection and anastomosis is associated with excellent survival and outcomes. ${ }^{18}$

As expected, in a study performed by the SCOTIA study group in 1995, they found that patients with left colon malignant obstruction had better bowel function if they had a segmental resection than if they had a subtotal colectomy, although overall morbidity and mortality was otherwise similar. ${ }^{19,20}$ If a cancer is the cause of obstruction and the patient can tolerate it, the appropriate segmental resection with high vascular ligation should be performed.

\section{Special Situations}

\section{Sigmoid Volvulus}

Flexible sigmoidoscopy and decompression in patients with sigmoid volvulus is successful in detorsing 85-95\% of patients with sigmoid volvulus. But it is contraindicated in patients with peritonitis or an acute abdomen. ${ }^{21}$ And if unsuccessful, urgent surgery is needed. In addition, because there is up to a $60 \%$ rate of recurrence, it is recommended that these patients still undergo surgery at time of original admission for sigmoid resection. $^{22}$

\section{Cecal Volvulus/Bascule}

Colonoscopic decompression is generally ineffective $(<30 \%$ of patients can be helped with colonoscopy), and these patients have a higher rate of ischemia, as a result surgery remains the 
primary treatment modality. In 1990, Rabinovici et al. reviewed the 568 cases reported in the literature and found that up to $20 \%$ of patients have a gangrenous cecum..$^{23}$ In addition, detorsing with cecopexy or performing a cecostomy had much higher rates of complication and recurrence. Primary resection is the primary method of management. The majority of these patients can be resected and reanastomosed, unless the patient is unstable, in which case a proximal diversion maybe needed or a second look operation.

\section{Stenting in Malignant Obstruction \\ Controversy and Recommendations}

Up to one third of patients with colorectal cancer in western countries present with near or complete mechanical obstruction due to tumor burden and require urgent management. Both acute and subacute obstructions from malignancy have high morbidity and mortality. Because of this, especially for left-sided lesions where resection is more complicated, stenting has been suggested as a tool to let patients move past the phase of acute obstruction and either be treated with systemic palliative or neoadjuvant chemotherapy without a delay for surgery or so that they can avoid emergent surgery. Since the early 1990s, a number of reports have been described using stents for the management of colonic obstruction. These studies have looked both the use of stents for palliative reasons and as a potential bridge to surgery (see Table 1).

\section{Palliation}

As a treatment for patients with incurable disease, a stent may lend patients the opportunity to get systemic chemotherapy and provide palliation without the morbidity of an operation. A Cochrane review of colonic stenting for palliation evaluated five randomized trials looking at stenting compared to surgery and found that surgery had a higher clinical success (99 vs. $78 \%$ ) but that the time to relief was shorter for stents and that morbidity and mortality was similar for their patients. ${ }^{24}$ In addition, a recent multicenter randomized trial of stenting versus surgery was closed early due to an unexpectedly high perforation rate in the nonsurgical arm. ${ }^{25}$ Still many centers use stenting for palliation with excellent results. ${ }^{26}$ The reality as that for many patients with advanced disease who are not good surgical candidates, stenting may allow palliation and earlier treatment. However, because of technical variability, it should be used at centers with experience in advanced endoscopic technique. In addition, when used for palliation, patients should be warned that they may need additional procedures and that there are high rates of long-term complications. ${ }^{27}$ So for patients fit for surgery, surgery is typically the procedure of choice.

\section{Bridge to Surgery}

For patients with acute obstruction who are sick, a stent may be able to hold them over to nutritional improvement and then resection or even neoadjuvant chemotherapy. For patients with combined liver/colon disease, a stent may allow deferral of the colectomy and allow treatment of the liver. In addition, because of the high morbidity and mortality of obstructing colon cancers, stents may turn an emergent procedure into an elective one, and patients can be optimized, prepped, and decrease surgical mortality from around $20 \%$ down to $5 \%$. Patients with resectable colon cancers can also decompress and have the rest of their colon evaluated to make sure that there are no synchronous lesions. In a paper by Vitale et al., up to $10 \%$ of the patients in their review had a synchronous cancer, and as a result of being able to have preoperative stenting, they were able to have a full evaluation and make a more educated surgical resection plan. ${ }^{28-33}$ In addition, a costeffectiveness analysis concluded that colonic stent insertion followed by surgery was more effective and less costly than

Table 1 Key randomized controlled trials in colonic stenting for malignant obstruction

\begin{tabular}{|c|c|c|c|c|c|c|c|}
\hline Author & Year & $\begin{array}{l}\text { No. patients } \\
\text { stented/ } \\
\text { surgery }\end{array}$ & $\begin{array}{l}\text { Stent } \\
\text { Success } \\
(\%)\end{array}$ & $\begin{array}{l}\text { Perforation } \\
\text { rate }\end{array}$ & Findings & Reason for stent & Other \\
\hline Fiori et al. ${ }^{34}$ & 2004 & $11 / 11$ & $100 \%$ & none & $\begin{array}{l}\text { Improved return of } \\
\text { function }\end{array}$ & Palliation & \\
\hline Cheung et al. ${ }^{35}$ & 2009 & $24 / 24$ & $83 \%$ & none & $\begin{array}{l}\text { SEMS reduced blood } \\
\text { loss, pain, leak, stoma }\end{array}$ & & $\begin{array}{l}\text { Time from SEMS to } \\
\text { surgery }<2 \text { week }\end{array}$ \\
\hline Pirlet et al. ${ }^{36}$ & 2010 & $30 / 39$ & $47 \%$ & $14 \%$ & & $\begin{array}{l}\text { Trial closed prematurely due to high } \\
\text { perforation rate in stent group }\end{array}$ & \\
\hline $\begin{array}{l}\text { Van Hooft } \\
\text { et al. }{ }^{31}\end{array}$ & 2011 & $47 / 51$ & $70 \%$ & $12 \%$ & & $\begin{array}{l}\text { Trial closed prematurely due to high rate } \\
\text { of morbidity on interim analysis }\end{array}$ & \\
\hline Alcantara et al. ${ }^{37}$ & 2011 & $15 / 13$ & $100 \%$ & $\mathrm{nr}$ & $\begin{array}{l}\text { SEMS reduced morbidity } \\
\text { and anastomotic leak }\end{array}$ & $\begin{array}{l}\text { Trial closed due to high rate of anastomotic } \\
\text { leak in emergency surgery group }\end{array}$ & $\begin{array}{l}\text { Surgery group } \\
\text { underwent lavage }\end{array}$ \\
\hline
\end{tabular}


emergency surgery, especially when looking at the patient's quality of life. ${ }^{25} \mathrm{~A}$ multi center study showed that colonic stenting relieved the obstruction in $93 \%$ of patients, and as a result, $92 \%$ of patients were able to undergo a single-stage resection and anastomosis within 8.6 days of stent placement, with only one patient having a perforation. ${ }^{38}$

Tan et al. performed a meta-analysis of randomized controlled trials of self-expanding metallic stents (SEMS) as a bridge to surgery versus emergency surgery for malignant leftsided large bowel obstructions. ${ }^{39}$ Their group that while as a bridge to surgery SEMS had a higher successful primary anastomosis and lower overall stoma rates, and 0 difference in complications or mortality, there was a high association with both clinical and silent perforation. In addition, technical and clinical successes were lower than expected overall. Cirocchi et al. ${ }^{40}$ conducted a similar meta-analysis and also found that clinical success was higher in the emergency surgery group. These authors however caution, as is important that in all of the RCTs performed, the numbers are small, and the majority of the studies did not look at long-term quality of life, cost, or oncologic outcome.

Because of the mixed findings of these studies, careful patient selection regarding the use of stenting is very important. Stenting of rectal tumors is generally avoided because they tend to migrate and cause pain. In addition, stenting at the splenic flexure and rectosigmoid may be more likely to perforate due to the angulation of the stents. New methodologies are being utilized to help minimize the risk of perforation. And for patients who have stents as a bridge to surgery, erosion and perforation may be less likely than surgery is performed in the early post-stenting period.

\section{Conclusions and Final Recommendations}

While there have been some changes in the diagnosis and management of large bowel obstruction, it remains a surgical emergency that is important for clinicians to understand and manage correctly. CT scan has taken over as the imaging modality of choice in the majority of cases. The most controversial issue to date is that of colonic stenting. As a palliative procedure, stenting should be used with caution and by those with advanced endoscopic experience. It is associated with high rates of reintervention and complications and so should be used with caution. As a bridge to surgery, it has not proven to be as beneficial as expected. And patients who are clearly resectable and can tolerate surgery should undergo surgery as the treatment of choice given both the short-term and longterm benefits. For the more complicated patients, stenting has been used with good success. This continues to evolve as there are many more surgical and endoscopic options available and as neoadjuvant therapy continues to evolve. Most importantly is the physician's focus on the patient's comorbidities, disease process, and technological technical complexity in order to make individual treatment decisions.

\section{References}

1. Byrne JJ. Large bowel obstruction. American journal of surgery. Feb 1960;99:168-178.

2. Athreya S, Moss J, Urquhart G, Edwards R, Downie A, Poon FW. Colorectal stenting for colonic obstruction: the indications, complications, effectiveness and outcome-5 year review. European journal of radiology. Oct 2006;60(1):91-94.

3. Lopez-Kostner F, Hool GR, Lavery IC. Management and causes of acute large-bowel obstruction. The Surgical clinics of North America. Dec 1997;77(6):1265-1290.

4. Burrell HC, Baker DM, Wardrop P, Evans AJ. Significant plain film findings in sigmoid volvulus. Clinical radiology. May 1994;49(5): 317-319.

5. Chapman AH, McNamara M, Porter G. The acute contrast enema in suspected large bowel obstruction: value and technique. Clinical radiology. Oct 1992;46(4):273-278.

6. Frager D, Rovno HD, Baer JW, Bashist B, Friedman M. Prospective evaluation of colonic obstruction with computed tomography. Abdominal imaging. Mar-Apr 1998;23(2):141-146.

7. Filippone A, Cianci R, Grassedonio E, Di Fabio F, Storto ML. Foursection multidetector computed tomographic imaging of bowel obstruction: usefulness of axial and coronal plane combined reading. Journal of computer assisted tomography. Jul-Aug 2007;31(4):499-507.

8. Filippone A, Cianci R, Storto ML. Bowel obstruction: comparison between multidetector-row $\mathrm{CT}$ axial and coronal planes. Abdominal imaging. May-Jun 2007;32(3):310-316.

9. Angelelli G, Moschetta M, Binetti F, Cosmo T, Stabile Ianora AA. Prognostic value of MDCT in malignant large-bowel obstructions. $L a$ Radiologia medica. Aug 2010;115(5):747-757.

10. Jacob SE, Lee SH, Hill J. The demise of the instant/unprepared contrast enema in large bowel obstruction. Colorectal disease : the official journal of the Association of Coloproctology of Great Britain and Ireland. Sep 2008;10(7):729-731.

11. Saunders MD. Acute colonic pseudo-obstruction. Best practice \& research. Clinical gastroenterology. 2007;21(4):671-687.

12. Luning TH, Keemers-Gels ME, Barendregt WB, Tan AC, Rosman C. Colonoscopic perforations: a review of 30,366 patients. Surgical endoscopy. Jun 2007;21(6):994-997.

13. Runkel NS, Hinz U, Lehnert T, Buhr HJ, Herfarth C. Improved outcome after emergency surgery for cancer of the large intestine. The British journal of surgery. Sep 1998;85(9):1260-1265.

14. Meyer F, Marusch F, Koch A, et al. Emergency operation in carcinomas of the left colon: value of Hartmann's procedure. Techniques in coloproctology. Nov 2004;8 Suppl 1:s226-229.

15. Gastinger I, Marusch F, Koch A, et al. [Hartmann's procedure indication in colorectal carcinoma]. Der Chirurg; Zeitschrift fur alle Gebiete der operativen Medizen. Dec 2004;75(12):1191-1196.

16. Pearce NW, Scott SD, Karran SJ. Timing and method of reversal of Hartmann's procedure. The British journal of surgery. Aug 1992;79(8):839-841.

17. ReMine SG, Dozois RR. Hartmann's procedure. Its use with complicated carcinomas of sigmoid colon and rectum. Archives of surgery. May 1981;116(5):630-633.

18. Poon RT, Law WL, Chu KW, Wong J. Emergency resection and primary anastomosis for left-sided obstructing colorectal carcinoma in the elderly. The British journal of surgery. Nov 1998;85(11):15391542.

19. Single-stage treatment for malignant left-sided colonic obstruction: a prospective randomized clinical trial comparing subtotal colectomy 
with segmental resection following intraoperative irrigation. The SCOTIA Study Group. Subtotal Colectomy versus On-table Irrigation and Anastomosis. The British journal of surgery. Dec 1995;82(12):1622-1627.

20. Tejero E, Mainar A, Fernandez L, Tieso A, Cuezva JF, San Jose A. New procedure for relief of malignant obstruction of the left colon. The British journal of surgery. Jan 1995;82(1):34-35.

21. Mangiante EC, Croce MA, Fabian TC, Moore OF, 3rd, Britt LG. Sigmoid volvulus. A four-decade experience. The American surgeon. Jan 1989;55(1):41-44.

22. Baker DM, Wardrop PJ, Burrell H, Hardcastle JD. The management of acute sigmoid volvulus in Nottingham. Journal of the Royal College of Surgeons of Edinburgh. Oct 1994;39(5):304-306.

23. Rabinovici R, Simansky DA, Kaplan O, Mavor E, Manny J. Cecal volvulus. Dis Colon Rectum. Sep 1990;33(9):765-769.

24. Sagar J. Colorectal stents for the management of malignant colonic obstructions. Cochrane database of systematic reviews (Online). 2011(11):CD007378.

25. van Hooft JE, Fockens P, Marinelli AW, et al. Early closure of a multicenter randomized clinical trial of endoscopic stenting versus surgery for stage IV left-sided colorectal cancer. Endoscopy. Mar 2008;40(3):184-191.

26. Sebastian S, Johnston S, Geoghegan T, Torreggiani W, Buckley M. Pooled analysis of the efficacy and safety of self-expanding metal stenting in malignant colorectal obstruction. Am J Gastroenterol. Oct 2004;99(10):2051-2057.

27. Gianotti L, Tamini N, Nespoli L, et al. A prospective evaluation of short-term and long-term results from colonic stenting for palliation or as a bridge to elective operation versus immediate surgery for large-bowel obstruction. Surgical endoscopy. 2013;27(3):832-842.

28. Vitale MA, Villotti G, d'Alba L, Frontespezi S, Iacopini F, Iacopini G. Preoperative colonoscopy after self-expandable metallic stent placement in patients with acute neoplastic colon obstruction. Gastrointestinal endoscopy. May 2006;63(6): 814-819.

29. Jimenez-Perez J, Casellas J, Garcia-Cano J, et al. Colonic Stenting as a Bridge to Surgery in Malignant Large-Bowel Obstruction: A Report from Two Large Multinational Registries. Am J Gastroenterol. Dec 2011;106(12):2174-2180.

30. Sara GG, Luciano DP, Diana RG. Management of Malignant Colonic Obstruction: Emergency Surgery Vs. Colonic Stenting. Ann Oncol. Jun 2011;22:v92-v93.
31. van Hooft JE, Bemelman WA, Oldenburg B. Colonic stenting versus emergency surgery for acute left-sided malignant colonic obstruction: a multicentre randomised trial (vol 12,pg 344, 2011). Lancet Oncol. May 2011;12(5):418-418.

32. Song LMWK, Baron TH. Stenting for acute malignant colonic obstruction: a bridge to nowhere? Lancet Oncol. Apr 2011;12(4): 314-315.

33. Mozdiak EA, Lewis MJV. Enteral Stenting in the Management of Obstructing Colonic Cancer: The City Hospital Experience. Gut. Apr 2011;60.

34. Fiori E, Lamazza A, De Cesare A, Bononi M, Volpino P, Schillaci A, \& Cangemi V. Palliative management of malignant rectosigmoidal obstruction. Colostomy vs. endoscopic stenting. A randomized prospective trial. Anticancer research . 2004;24(1):265-268.

35. Cheung HYS, Chung CC, Tsang WWC, Wong JCH, Yau KKK, \& Li MKW. Endolaparoscopic approach vs conventional open surgery in the treatment of obstructing left-sided colon cancer: a randomized controlled trial. Archives of Surgery. 2009;144(12):1127.

36. Pirlet IA, Slim K, Kwiatkowski F, Michot F, \& Millat BL. Emergency preoperative stenting versus surgery for acute left-sided malignant colonic obstruction: a multicenter randomized controlled trial. Surgical endoscopy. 2011;25(6):1814-1821.

37. Alcantara M, Serra-Aracil X, Falco J, Mora L, Bombardó J, \& Navarro S. Prospective, controlled, randomized study of intraoperative colonic lavage versus stent placement in obstructive left-sided colonic cancer. World journal of surgery. 2011;35(8): 1904-1910.

38. de Gregorio MA, Mainar A, Tejero E, et al. Acute colorectal obstruction: stent placement for palliative treatment-results of a multicenter study. Radiology. Oct 1998;209(1):117-120.

39. Tan CJ, Dasari BVM, Gardiner K. Systematic review and metaanalysis of randomized clinical trials of self-expanding metallic stents as a bridge to surgery versus emergency surgery for malignant leftsided large bowel obstruction. The British journal of surgery. 2012;99(4):469-476.

40. Cirocchi R, Farinella E, Trastulli S, Desiderio J, Listorti C, Boselli C, Parisi A, Noya G, \& Sagar J. Safety and efficacy of endoscopic colonic stenting as a bridge to surgery in the management of intestinal obstruction due to left colon and rectal cancer: a systematic review and meta-analysis. Surgical oncology Mar 2013;22(1):14-21. doi:10.1016/j.suronc.2012.10.003. 